ISSN 0819-2642

ISBN 0734026331

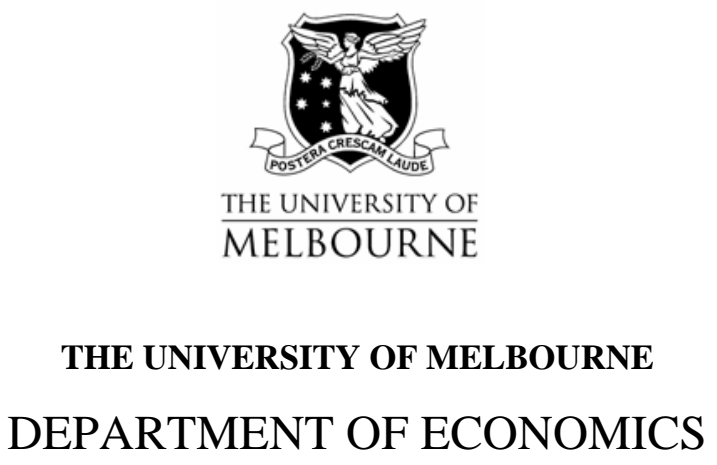

RESEARCH PAPER NUMBER 975

OCTOBER 2006

\title{
Subject Pool Effects in a Corruption \\ Experiment: A Comparison of Indonesian Public \\ Servants and Indonesian Students
}

\author{
by \\ Vivi Alatas \\ $\&$ \\ Lisa Cameron \\ $\&$ \\ Ananish Chaudhuri \\ \& \\ Nisvan Erkal \\ \& \\ Lata Gangadharan
}

Department of Economics

The University of Melbourne

Melbourne Victoria 3010

Australia. 


\title{
Subject Pool Effects in a Corruption Experiment: A Comparison of Indonesian Public Servants and Indonesian Students ${ }^{1}$
}

\author{
Vivi Alatas ${ }^{\mathrm{a}}$, Lisa Cameron ${ }^{\mathrm{b}}$, Ananish Chaudhuri ${ }^{\mathrm{c}}$, Nisvan Erkal ${ }^{\mathrm{b}, 2}$, Lata \\ Gangadharan ${ }^{b}$ \\ a World Bank, Jakarta 12190, Indonesia. (e-mail: valatas@worldbank.org) \\ ${ }^{\mathbf{b}}$ Department of Economics, University of Melbourne, VIC 3010, Australia. \\ (e-mail: \{lcameron, latag, n.erkal\}@unimelb.edu.au) \\ ${ }^{\text {c }}$ Department of Economics, University of Auckland, Private Bag 92019, Auckland, \\ New Zealand. (e-mail: a.chaudhuri@auckland.ac.nz)
}

September 2006

\begin{abstract}
We report results from a corruption experiment with Indonesian public servants and Indonesian students. Our results suggest that although both subject pools show a high level of concern with the extent of corruption in Indonesia, the Indonesian public servant subjects have a significantly lower tolerance of corruption than the Indonesian students. We find no evidence that this is due to a selection effect. The reasons given by the public servants for either engaging in or not engaging in corruption suggest that the differences in behavior across the subject pools are driven by their different real life experiences. For example, when abstaining from corruption public servants more often cite the need to reduce the social costs of corruption as a reason for their actions, and when engaging in corruption they cite low government salaries or a belief that corruption is a necessary evil in the current environment. In contrast, students give more simplistic moral reasons. We conclude by arguing that experiments such as the one considered in this paper can be used to measure forward-looking attitudinal change in society and that results obtained from different subject pools can complement each other in the determination of such attitudinal changes.
\end{abstract}

JEL Classification: C91, D73, O12, K42

Keywords: Corruption, Experiments, Subject Pool Effects

\footnotetext{
${ }^{1}$ We would like to thank Charles Noussair and the participants of the Experimental Economics Workshop (2006) at the University of Melbourne for their comments. Daniel Piccinin and Revy Sjahrial have provided excellent research assistance. We are grateful to the Australian Research Council and the World Bank for their financial assistance.

${ }^{2}$ Corresponding author.
} 


\section{Introduction}

This paper compares the behavior of Indonesian public servants with the behavior of Indonesian students in a corruption experiment. It builds on Cameron et al., (2006), where we used an experimental design to explore whether there are systematic cultural differences in the propensities to engage in and punish corrupt behavior, and found that student subjects in Indonesia are less tolerant of corruption than student subjects in India, Singapore, and Australia. ${ }^{3}$ In this paper we explore to what extent the low tolerance level of the students in Indonesia is shared by the public servants in Indonesia.

The experiment that we report in this paper can be classified as both an "artefactual" and a "framed" field experiment according to the taxonomy developed by Harrison and List (2004). ${ }^{4}$ There has been a tradition in experimental economics of relying on non-emotive neutral language in experiments. However, evidence is beginning to gather that providing a context for the experiment might be desirable, especially in cases when the participants have a direct experience with the particular context being studied. For example, both Cooper et al., (1999) and Harrison and List (2005) find that introducing a context that expert subject pools recognize from their past experiences triggers an

\footnotetext{
${ }^{3}$ The results in Cameron et al., (2006) are consistent with the outcome of the surveys conducted by Transparency International in 44 countries which showed that Indonesians were the most optimistic about future corruption reduction while Indians were amongst the most pessimistic. See unpan1.un.org/intradoc/groups/public/documents/APCITY/UNPAN016537.pdf. The World Bank's "voice and accountability" index also puts Indonesia among those countries that have achieved a sharp improvement in corruption reduction since 1996 (Kaufman, 2005).

${ }^{4}$ That is, we examine behavior using a non-standard subject pool and explicitly introduce context from the field to the laboratory experiment by using loaded language and roles specific to the context. Harrison and List (2004) classify all experiments into four categories: conventional lab experiments, (that employ a standard subject pool of students, an abstract framing, and an imposed set of rules); artefactual field experiments (same as conventional lab experiments but with a non-standard subject pool), framed field experiments (same as artefactual field experiments but with field context in either the commodity, task, or information set that the subjects can use), and natural field experiments (same as a framed field experiment but where the environment is one where the subjects naturally undertake these tasks and where the subjects do not know that they are in an experiment).
} 
application of learning from those past experiences. ${ }^{5}$ Hence, depending on the issue under study, framed experiments might better capture true preferences or attitudes (Cooper et al., 1999; Cooper and Kagel, 2003; Harrison and List, 2004).

A framed experiment allows us to analyse both the behavioral differences between the public servant and student subjects, and the reasons for these differences. The use of public office for private gain is seen as an important source of corruption in many developing countries. ${ }^{6}$ Hence, the blame for corruption in developing countries is often laid at the feet of corrupt public servants. This conventional wisdom leads one to expect the public servant subjects in Indonesia to be more tolerant of corruption than the student subjects in Indonesia.

The differences in behavior may be due to an experience effect if the differing experiences of the two groups lead to the adoption of different norms of behavior. Indonesian public servants are frequently exposed to corruption in their workplace ${ }^{7}$ while Indonesian students' exposure to corruption is possibly more limited and indirect. Hence, an experience effect would be present if a high exposure to corruption in the public service leads public servants to adopt a more tolerant norm of corrupt behavior, the difficulty of living on low salaries makes them more susceptible to the temptation of corruption, or a more direct exposure to corruption and its costs increases their aversion to it. Alternatively, the differences in behavior may be driven by a selection effect if those who choose to join

\footnotetext{
${ }^{5}$ This is consistent with the findings in cognitive psychology, See, as cited in Cooper et al., (1999), Gick and Holyoak (1980), Perkins and Salomon (1988), and Salomon and Perkins (1989).

6 See, for example, the World Bank's analysis and anti-corruption initiative at http:/web.worldbank.org/WBSITE/EXTERNAL/TOPICS/EXTPUBLICSECTORANDGOVERNANCE/EX TANTICORRUPTION/0,,contentMDK:20222047 menuPK:384461 pagePK:148956 piPK:216618 theSite PK:384455,00.html. See also the discussion in Bardhan (2006).

${ }^{7}$ Indonesia is currently ranked by Transparency International as one of the most corrupt countries in the world (with a ranking of 137 among the 158 countries ranked). See www.transparency.org/policy_research/surveys_indices/cpi.
} 
the public service are inherently more or less corrupt than those who are attracted to the private sector.

The extent of differences in behavior across subject pools has been of considerable methodological interest to experimental economists. The literature that has sought to examine subject pool effects has largely explored gender and educational differences amongst students. ${ }^{8}$ Recently there has been an increase in the use of non-standard subject pools in experiments. ${ }^{9}$ The results on whether the subject pool matters are mixed. Carbone (2005), for example, finds very little effect of demographics on behavior in a life-cycle consumption experiment conducted on a random sample of the population. Kovalchik et al., (2005) find no effect of age on behavior in a variety of economic decision-making experiments. In contrast, Croson and Gneezy (2004) document a number of differences by gender. Alevy et al., (2006) find that financial market professionals outperform student subjects in experiments examining herd behavior in financial markets. Fehr and List (2004) find that CEOs exhibit considerably more trustful and trustworthy behavior than students. Finally, List (2003) finds that the experience of sportscard traders eliminates what is known as the endowment effect (that a good's value increases once it becomes a part of an individual's endowment). None of these papers explore subject pool effects in the case of a corruption experiment.

Our findings reveal that the Indonesian public servants are substantially less likely to engage in corruption than the Indonesian students. This is in an environment where there

\footnotetext{
${ }^{8}$ There has also been a focus on whether business and economics students (who make up a disproportionate share of the student subjects) differ from the other students.

${ }^{9}$ The non-standard subject pools used include financial market traders (Alevy et al., 2006), sportscard dealers (List, 2003; Harrison and List, 2005), nurses (Cadsby and Maynes, 1998; Barr et al., 2004), CEOs (Fehr and List, 2004), managers in Chinese state-owned enterprises (Cooper et al., 1999), public affairs officials (Potters and van Winden, 1996), and a random sample of the general population (Carbone, 2005). Only a subset of these studies directly compares the results from the non-standard subject pool with the results from the student subject pool.
} 
were significant monetary gains to be made from acting corruptly and where, as we explain in the next section, we went to great lengths to ensure anonymity and distance from the workplace. The results further suggest that the difference in behavior is not driven by a selection effect, but is rather a consequence of experience in the public sector.

The results from both the public servant and student subject pools are consistent in that they show a high level of concern with the extent of corruption in Indonesia. That the results differ sharply by subject pool highlights the need to conduct experiments on either the relevant subject pool or across a number of different subject types. In the context of a corruption experiment, experiments conducted with students as subjects are open to criticism on the basis that because students are likely to be idealistic and have little experience of the real world, their behavior and views may not reflect those of society at large. On the other hand, if regime change is driven from the grass roots, often with vigorous student involvement (as was the case in Indonesia in 1998), student attitudes might well be an appropriate gauge of a country's future with regard to corruption. As far as the Indonesian public servants are concerned, since they are in a role in which they regularly have to decide whether to engage in, tolerate, or dissuade corrupt acts, their attitudes to corruption may be a more relevant, or at least an equally important, gauge of the extent and future of a country's corruption problems.

The rest of the paper is structured as follows. Section 2 details the experimental design and procedure. Section 3 compares the results from the student pool with those from the public servant pool, and explores the reasons for the differences. Section 4 concludes by offering an interpretation of our results and discussing their implications. 


\section{Experimental Design and Procedures.}

\section{$2.1 \quad$ Design}

The experiment is based on the three-person, sequential-move game introduced in Cameron et al. (2006). It is intended to capture a typical and pervasive bribery problem in many developing countries, where, for example, the manager of a firm may offer a bribe to avoid complying with an environmental or a health regulation. Figure 1 contains an extensive-form representation of the game, where all of the payoffs are denoted in experimental dollars.

The players are denoted as the "Firm,” "Government Official,” and "Citizen.” They start with an endowment of 60, 30, and 80 experimental dollars respectively. The Firm moves first and must decide whether to offer a bribe to the Government Official, and if so, how much to offer. It can choose a bribe amount $B \in[4,8]$. It costs the Firm two experimental dollars to offer a bribe and the Firm incurs this transaction cost regardless of whether the bribe is accepted. If a bribe is offered, the Official can either accept or reject the bribe. Acceptance of the bribe implies favorable treatment of the Firm. It increases the payoffs of both the Firm and the Official by 3B, but decreases the payoff of the Citizen by 7B. ${ }^{10}$ As mentioned above, the payoff increase that the firm experiences may represent, for example, the benefit from avoiding a regulation. We assume that the bribery has a significant impact on society. This is captured by the large decrease in the Citizen’s payoff.

\footnotetext{
${ }^{10}$ We assume that the Official's payoff increases by 3B even though the amount of bribe paid by the Firm is $\mathrm{B}$ due to a difference in the marginal utility of income for the Firm and the Official. Since the income earned in the public service is likely to be lower than that earned in private firms, the same amount of money can be assumed to have a lower marginal utility value to the Firm than to the Official. Abbink, Irlenbusch and Renner (2002) make a similar assumption. This assumption also has the additional advantage of helping us prevent negative total payoffs.
} 
The Citizen observes the decisions made by the Firm and the Official and can punish them for the act of bribery by choosing an amount $\mathrm{P} \in[2,12]$ in penalty. Punishment is costly to the Citizen and reduces the Citizen's payoff by the amount of the punishment, P. However, it imposes a monetary sanction on the Firm and Official by reducing their payoffs by 3P. Hence, the net benefit to the Firm and the Official from the corrupt transaction is 3B - 2 - 3P and 3B - 3P respectively.

We have chosen to conduct a one-shot game because in a one-shot game the punishment has no economic benefit to the Citizen. Since the decision to punish is not affected by the anticipation of possible future economic gains, the Citizens' willingness to punish helps us capture their tolerance of corruption more directly. In other words, the Citizens who choose to punish in a one-shot game would have even more incentive to punish in a multi-period game since by doing so, they can possibly deter corruption and decrease the harm they suffer. The one-shot nature of the game also helps us avoid the issues associated with repeated games, such as signaling, reputation formation, and serial correlation in decisions.

We have also deliberately chosen to use emotive terms such as "bribe" and "punishment" in the instructions. As mentioned in the introduction, the use of a meaningful context might better capture behavior in field settings than the use of neutral language. ${ }^{11}$ Further, as discussed above, context may be an important element in revealing subject pool differences as they trigger considerations of participants' own experiences which may differ across the different subject pools. Finally, as Harrison and List (2004) indicate, "it is

\footnotetext{
${ }^{11}$ We ran both neutral-language and loaded language experiments with students in Australia to see whether the behavior in the loaded-language experiments is different from the behavior in the neutral-language experiments. We find that in the neutral-language sessions, the behavior is closer to the game theoretical prediction. That is, the subjects bribe more often, accept more often, and punish less often. These results indicate that the loaded-language experiment is able to capture the subjects' tolerance of corruption.
} 
not the case that abstract, context-free experiments provide more general findings if the context itself is relevant to the performance of subjects (p. 1022).”

\section{$2.2 \quad$ Procedure}

The experiments were run at the University of Indonesia and the Sekolah Tinggi Ilmu Administrasi (STIA), which is a training college for public servants. Both institutions are located in Jakarta. The student subject pool consisted of third-year undergraduate and postgraduate students. 180 student subjects and 147 public servant subjects participated in the experiments. Each subject participated only once and in only one role. Since each play of the game involves three subjects, this gives us 60 plays of the game (i.e., 60 independent observations) for the students and 49 for the public servants.

All the sessions were run as non-computerized experiments. Each experimental session lasted about an hour. At the beginning of each session subjects were asked to come to a large lecture theatre. Each session consisted of at least 30 subjects. The subjects, on entering the room, were randomly designated as Firms, Officials, or Citizens. Each group was located apart from the others in a recognizable cluster. Thus, each group could see the members of the other groups, but individual subjects were unaware of which three specific subjects constituted a particular Firm-Official-Citizen trio and would not learn this information at any point during the session.

At the beginning of each session, each subject received a copy of the instructions, which were then read out loud to them. To avoid experimenter effects, the experiments were conducted by the same team of experimenters, which included an Indonesian researcher and an Indonesian research assistant. The subjects were given a number of examples explaining how the payoffs would be calculated for specific bribe and 
punishment amounts. Then, the subjects playing the role of a Firm were asked to make their decisions. The record sheets with their bribe amounts were then collected and distributed by the experimenter to the corresponding Officials. After the Officials made their decisions, the corresponding Citizens were informed whether a bribe was offered and whether it was accepted. The experiment ended after the Citizens decided whether to punish or not. The decisions made by all of the subjects were entered into a spreadsheet which generated their payoffs. The subjects were paid at the end of each session after the payoffs were converted into cash. To guarantee parity in the payoffs to the different type of players (Firm, Official, and Citizen), we used a different conversion rate for each type. The conversion rates also took into account the differing income levels of the public servants and students. These conversion rates were public information.

Each student subject made on average US $\$ 8^{12}$ in the experiment while each public servant subject made US\$12. Hence, the average earning of the public servants was 1.525 times higher than the average earning of the student subjects. The average hourly wage of the public servants, across all ranks and levels, is approximately equal to 55 US cents. ${ }^{13}$ Assuming that students would receive an amount close to the minimum wage if employed (which in Jakarta is equal to 31 US cents per hour), the average hourly wage of the public servants is approximately 1.77 times higher than that of the students. These figures imply that the average ratio of experimental earnings to actual hourly wages was approximately $22 \%$ for the public servants and $26 \%$ for the students. In addition, the public servant subjects made decisions under reasonably high stakes as their average earnings in the experiment were approximately 22 times their average hourly wage rate.

\footnotetext{
12 This has approximately the same purchasing power as US\$15-20 in the US.

${ }^{13}$ This figure was obtained from the website containing information on the determination of civil servant salaries in Indonesia. See http://www.pu.go.id/sekjen/biro\%20hukum/perpres/perpres1_06.html.
} 
After the experiment, the subjects filled out a demographic survey, which asked them a series of questions regarding their age, gender, field of study, work experience, expenditure levels, religion, ethnicity, and level of exposure to corruption. They were also asked to explain the motivation for their decisions. The student subjects were additionally asked whether after graduating they wished to work in the private or public sector. ${ }^{14}$

In designing the experiment, we were acutely aware of the need for anonymity especially in the case of the public servants - between the subjects and the experimenters, and among the subjects themselves. Levitt and List (2006) model the choices made in experiments as being the outcome of two, possibly competing, forces: payoff maximization and non-pecuniary "moral" costs or benefits. The moral cost of a decision reflects the financial externality the decision imposes on others, social norms, and "scrutiny effects." The scrutiny effects reflect the desire on the part of subjects to send a signal to the experimenter or be perceived by the experimenter in a certain way. Levitt and List (2006) argue that moral concerns are greater when an individual's actions are more closely scrutinized and that the unnatural level of scrutiny in an experimental lab can bias the results away from what would be observed in the real world. ${ }^{15}$

\footnotetext{
${ }^{14}$ The instruction, record, and survey sheets are available from the authors upon request. The documents were prepared in English, translated into Indonesian by a native Indonesian speaker, and then checked by both a native Indonesian speaker who is fluent in English and a native English speaker who can read Indonesian.

${ }^{15}$ Levitt and List (2006) cite people behaving differently in front of their children as one example of the scrutiny effect. The scrutiny effect is particularly problematic if one wishes to use the experimental results in a predictive manner. For example, having observed that a father does not cross a road against a red light in front of his children, one would not necessarily want to predict that he would not cross against red if on his own. However, in our context there is no supposition that the lab results are predictive in this sense. That is, we would not predict that a subject who does not engage in corruption in the lab will not be corrupt when faced with the realities of the real world, such as living on a low government salary. Rather, we take the differences in the lab results across the different subject pools as indicative of the differences in the underlying attitudes to or tolerance of corruption. In the context of the example given above, note that an observation that parents in congested urban areas are less likely to cross against a red light in front of their children than parents in sparsely populated rural areas is likely to contain information regarding the differences in the underlying attitudes - that urban parents view crossing with the green light as a more
} 
The concern in the context of our experiment is that the observed behavioral differences between the public servants and the students may be due to the presence of a more severe scrutiny effect amongst the public servants. We took a number of steps to reduce this possibility. First, we conducted the public servant experiments at the training college for public servants, STIA, rather than at a particular government ministry or somewhere closely associated with their place of work. STIA trains public servants from all across Indonesia. Our sample covered people from over 60 different ministries and government offices coming from as far as Aceh in the east to Papua in the west. The experiments were thus conducted far from the participants' place of work. Second, the experiments with the public servants were conducted on a Saturday as part of a college festival and, hence, outside the normal study structure and not in the presence of any faculty or college employees. Third, we explained at the start of each session that the game was to be played anonymously. The participants were told that they would not know who they were matched with. The participants were assigned a code that was used to match the decisions of the different members of each group, to link their decisions with the answers in the surveys, and to make the payments. The researchers used an irreversible process whereby no record was retained of how the code related to the individuals. This was stated out loud and stressed several times at the start of each session. Fourth, to ensure privacy throughout the decision-making process, we made sure that the participants sat at a distance from each other that prevented their neighbours from seeing their decisions. Fifth, to reduce the probability that public servant subjects thought that we were interested in their behavior as public servants, we announced at the start of each session that we were

important safety lesson to instil in children than parents from the country. It is this kind of a comparative result that we seek in this paper. 
conducting these experiments at a number of educational colleges around the country and the survey, which asked them about their reasons for acting as they did (which the subjects were only made aware of and received after they had made their decisions in the experiment), was deliberately structured to appear as though there was no focus on public servants. For example, it asked generally about work experience and whether they worked in the private or public sector. ${ }^{16}$

\section{Results}

We start our analysis by discussing the differences in the demographic variables for the student and public servant pools respectively. Table 1 presents the summary statistics. It shows that, as expected, the public servants were on average older than the students (with an average age of 30.5 as compared to 20.6) and had more work experience. Specifically, while the public servants had 8.5 years of work experience on average (ranging from 1 to 30 years), the students had fewer than 5 months. A larger proportion of the public servants were male (75\% versus $42 \%$ ) and Muslim (85\% versus $66 \%$ ). The public servants also came from a wider array of ethnic groups. Only $36 \%$ of them were from the dominant Javanese ethnic group as opposed to $49 \%$ of the students. Finally, as anticipated, the public servants had higher expenditure levels. ${ }^{17}$

Table 1 also presents the subjects’ answers to questions about their contact with corruption. As anticipated, a much larger proportion of the public servants reported coming

\footnotetext{
${ }^{16}$ It is also worth mentioning that in the post-experimental survey responses, none of the 147 public servants stated that their decisions were affected by any aspects of scrutiny.

${ }^{17}$ The expenditure level of the public servants was on average 2.2 times higher than that of the students. This is expected as the public servants are older and would have families to take care of. The higher expenditure levels of the public servants could also reflect the income levels of their spouses or other adults living in the household.
} 
into contact with corruption through their work (55\% versus 9\%). Interestingly, the students and the public servants had similar amounts of exposure to corruption outside the workplace (reported by $33 \%$ of the students versus $32 \%$ of the public servants). The students more often reported coming into contact or hearing about corruption through family and friends or the mass media.

In summary, the students differed from the public servants in two important ways: (i) the students had a much more limited personal experience of corruption in the real world, and (ii) $81 \%$ of the students stated that they intend to work in the private sector after graduating. We control for the demographic variables presented in Table 1 in the statistical tests below. Moreover, we use the data from the student subjects who stated that they intend to work in the public sector to examine the extent to which the differences in behavior can be explained by selection effects.

Figure 2 shows the distribution of bribes for the student and public servant subject pools respectively. Table 2 presents summary statistics of behavior and t-tests of differences in means. ${ }^{18}$ It shows that $78 \%$ of the student subjects in the role of the Firm chose to bribe while only $47 \%$ of the public servants chose to bribe. This is a large difference. As shown in Table 2, it is strongly statistically significant with a p-value of $0.0005{ }^{19}$ The students also offered larger bribes on average. The mean positive bribe amount was 7.3 for the students versus 6.7 for the public servants (p-value $=0.04$ ).

Figure 3 shows the acceptance rates of participants in the role of the Government Official. Bribes were accepted $79 \%$ of the time by the student subjects and only $30.4 \%$ of

\footnotetext{
${ }^{18}$ We also conducted non-parametric rank sum tests of differences in distribution. The results are the same as the reported t-tests and are available from the authors upon request.

${ }^{19} 47 \%$ is an extremely low bribery rate. For example, with the same experiment, the bribery rate was $89 \%$ among the Australian student subjects and $84 \%$ among the Singaporean student subjects (Cameron et. al., 2006).
} 
the time by the public servant subjects (p-value $<0.0001$ ). The low bribery and acceptance rates of the public servants mean that there were very few public servants who got the opportunity to make a decision in the role of the Citizen. Of the 49 Citizen subjects, only 7 had the opportunity to punish. Punishment behavior is represented in Figure 4. It shows that the punishment rate was higher amongst the public servants, again indicating a lower tolerance of corruption (71\% versus 59\%). However, this difference is not statistically significant ( $\mathrm{p}$-value $=0.56)$. This could be due to the small number of observations in the sample for public servants.

Table 3 presents the regression results that control for whether the participant is a public servant or a student (to capture the subject pool effect), male, from a rural area, Javanese, has experienced corruption in his/her workplace, ${ }^{20}$ and whether a student intends to work in the public sector (to capture the selection effect). We chose to focus on these variables because they are the ones of interest in the existing literature and/or because they were the only ones that were statistically significant in any specification. Notably, controlling for the income and expenditure levels of the subjects in the regressions never yielded statistically significant results (and hence these variables are not included in the reported results). This leads us to conclude that the differences in the living standards and hence the differences in the "real" magnitude of the stakes across the different participants are not driving our results. In addition to the variables listed above, the regressions for the acceptance behavior also include a variable on the size of the bribe that was offered. Since the sample size for the punishment behavior of the public servants was too small to be meaningful, the results for the punishment behavior are not reported.

\footnotetext{
${ }^{20}$ As we discuss in Section 3.2 below, this is one of the four ways in which we seek to identify the effect of experience on behaviour.
} 
The coefficients on the public servant dummy are in every case statistically significant and consistent with the results of the t-tests. That is, the public servant subjects are significantly less likely to offer a bribe and less likely to accept a bribe. In cases when they did offer a bribe, the amount of the bribe was smaller. The results also reveal that being male has a significant effect only on the propensity to bribe. ${ }^{21}$ Moreover, being from Java is associated with a lower probability of offering a bribe.

Columns 7-8 in Table 3 present a second set of results for the acceptance behavior which allow the effect of the amount of the bribe to vary with whether the subject is a student or a public servant. These show that students differ from public servant subjects in the way they react to the bribe amount. While the acceptance behavior of the public servants is unaffected by the bribe amount, the students show a higher willingness to accept a bribe when the bribe amount is higher.

Having considered the differences between the two subject pools, we now turn our attention to a detailed analysis of the selection and experience effects.

\subsection{Selection Effect}

To capture the selection effect, as mentioned above, we have created a dummy variable "intention to work in government" which is equal to one if the student subject stated that s/he intends to work in the public sector and zero otherwise. The coefficient of this variable tells us to what extent the strong difference in behavior between the students and the public servants is due to a selection effect (as opposed to an experience effect).

\footnotetext{
${ }^{21}$ Gender does not affect the other decisions significantly. We undertake a far more comprehensive analysis of the gender differences in the propensities to engage in corruption using a similar experimental set-up and data from Australia, India, Indonesia and Singapore in Alatas et al., (2006) and find that there is a significant gender difference in the Australian sample only.
} 
As reported in Table 3, in none of the cases is the behavior of those students who intend to work in the government in the future different from the behavior of the rest of the students. However, their behavior is very different from that of the public servants. A test of equality of coefficients shows that both the bribe and the acceptance rates of the students who intend to work in the public sector are significantly higher than those of the public servant subjects ( $p=0.04$ and 0.06 respectively). Thus, the results suggest that selection does not play an important role in explaining the differences in the behavior of the two subject pools.

\subsection{Experience Effect}

We explore four different ways of examining the effect of experience on behavior. First, since we find no evidence of a selection effect, the public servant dummy variable captures the effect of experience in the public service. Second, we constructed a length of tenure variable which captures how important the extent of the experience in the public service is. Third, the coefficient on the variable reflecting exposure to corruption in the workplace indicates whether experience in a corrupt workplace affects behavior. Fourth, the reasons given by the subjects for their behavior shed considerable light on the role the public servants' work experience plays in explaining the behavioral differences between the subject pools.

Of the first three variables, only the public service indicator is consistently statistically significant (Table 3). The length of tenure variable is never significant (and hence is not included in the reported regressions). The variable reflecting experience with corruption in the workplace is negative and significant at the $10 \%$ level in the bribery probit $(\mathrm{p}=0.10)$, indicating that working in an environment where one frequently gets 
exposed to corruption may make one less tolerant of corruption. It is positive and almost significant at the $10 \%$ level $(\mathrm{p}=0.13)$ in the bribe amount equation, indicating that if one has decided to bribe, experience with corruption in the workplace is associated with offering a larger amount of bribe.

As far as our fourth approach is concerned, the reasons given by the subjects for their behavior were in response to open-ended questions. We have grouped these responses into the (non-mutually exclusive) categories shown in Table 4, which presents the breakdown of such responses by subject pool and decisions. We explore the explanatory power of these reasons by reporting the t-tests of differences in means. One of the most noticeable differences between the public servant and student subjects is that the public servants more often cited experience-related reasons for their decisions - both when acting corruptly and when not. For example, significantly more of the public servant subjects than the student subjects who chose to offer a bribe did so on the grounds that it was necessary given the current Indonesian environment (83\% versus 36\%, with the difference being statistically significant at the $5 \%$ level). Further, $46 \%$ of the public servant subjects who did not offer a bribe stated that they did this to reduce corruption and its associated social costs. Such a response was not given by any of the students in our sample. A further $18 \%$ of the public servants stated that they did not offer a bribe because it is not in the firm's (and the firm's employees') best interests in the long run. Only 3\% of the students gave a similar explanation for their behavior. The student subjects who did not bribe were significantly more likely to give simplistic moral explanations. Reasons such as "I did not bribe because bribery is prohibited by my religion” were given by $77 \%$ of the students as opposed to $35 \%$ of the public servants. 
Looking at the responses of the public servants in the role of the Government Official, we find that $43 \%$ of them accepted a bribe on the basis that it is either necessary for firms to offer bribes and that by accepting the bribe, they will be able to help the firms, ${ }^{22}$ or that it is necessary given the low salaries of public servants. In contrast, only $11 \%$ of the student subjects who accepted a bribe gave one or both of these reasons. ${ }^{23}$

Although the sample size for the public servants in the role of the Citizen is very small, the patterns of behavior are similar to those found for the subjects in the role of the Firm and the Government Official. The two public servants who had the chance to punish and chose not to stated that they did not punish because the bribe either is necessary or may be for a good purpose. Such a response was given by only slightly more than half of the student subjects. Moreover, $40 \%$ of the public servant subjects (as compared to only $27 \%$ of the student subjects) who chose to punish said that they did so to reduce corruption. $^{24}$

Another striking difference across the two groups is that the student subjects indicated with much greater frequency that they made their decisions to maximize their payoffs. $53 \%$ of the students in the role the Firm, $62 \%$ of the students in the role of the Government Official, and 35\% of the students in the role of the Citizen gave this reason in contrast with $2 \%, 4 \%$, and $0 \%$ of the public servant subjects respectively. All of these differences are statistically significant.

\footnotetext{
${ }^{22}$ In Indonesia, as in many developing countries, it can be necessary for a public official to distribute money to other officials in order to get forms processed, etc. Hence, by accepting a bribe from a firm, they are able to help the firm by distributing the money to other officials as needed.

${ }^{23}$ These figures are the sum of the two categories "necessary for firms to bribe" and "necessary because salaries are low." The difference between this sum for the student and the public servant subjects is significant at the $5 \%$ level.

${ }^{24}$ Given the small sample sizes for Citizens, this difference is insignificantly different from zero.
} 
These responses suggest that, consistent with the findings in the experimental literature, the public servants engaged to a greater extent with the context of the experiment. It is also suggested in the literature that the context effect would be larger for the public servants when they are in the role of the Official. We do find that the difference between the behavior of the two subject pools is the largest in this instance and more strongly statistically significant. The acceptance rates are $48.4 \%$ lower amongst the public servants than amongst the students, whereas the bribery rates are $31.4 \%$ lower.

\section{Conclusion}

This paper presents results from an artefactual and framed field experiment studying corruption. We find that the Indonesian public servant subjects are significantly less likely to engage in corruption than the Indonesian student subjects. We do not find any evidence of this being driven by a selection effect in that the behavior of those students who desire to work in the public sector does not differ significantly from the behavior of the rest of the students. The reasons given by the public servants for either engaging in or not engaging in corruption suggest that the differences in behavior across the two subject pools is driven by their different real life experiences.

The finding that a more direct experience with corruption is associated with a lower tolerance of corrupt acts may be explained in terms of the recent institutional changes in Indonesia. The advent of democracy and a free press have allowed widespread public condemnation of the highly concentrated and visible corruption that was so prevalent under President Suharto. ${ }^{25}$ The Indonesian public servants may have a lowered tolerance of

\footnotetext{
${ }^{25} \mathrm{~A}$ consequence of this change of sentiment has been the election of the current government, largely on an anti-corruption platform.
} 
corrupt transactions due to an increased level of monitoring of potentially corrupt activities. Alternatively, all the discussions of the negative impact of corruption on economic growth may have led them to aspire to make a positive difference given their critical positions.

The behavioral differences we observe across the two subject pools do not necessarily limit the usefulness of experiments that use student subjects. Rather, they highlight the need for careful consideration and selection of relevant subject pools, in light of the context being studied and the relevance of the subject pool to the policy objective. Data from different subject pools can be used to illuminate different aspects of the same problem. In the context of corruption, our paper suggests that experimental methodology can be used to elicit forward-looking estimates of corruption that indicate a population's propensity to press for and support anti-corruption institutional change. ${ }^{26}$ Student subjects are more representative of the general population than the subjects drawn from a specific profession. In the current context, they are the population that is likely to agitate for policy change. A comparison of student attitudes across time or countries can reveal the extent of the mood for change (Cameron et al., 2006). On the other hand, public servants are often an integral part of the corruption problem and their attitudes are an important, but different, component of the difficulty of combating corruption or otherwise of instituting change.

\footnotetext{
${ }^{26}$ Such forward-looking measures may be really important for policy-makers. The most frequently used measures of corruption, such as the Transparency International Corruption Index, measure people’s perceptions of the extent of corruption in the recent past. See "Digging for Dirt," The Economist, March 18, 2006. Several people have raised concerns about the reliability of these measures. See, for example, Olken (2006).
} 


\section{References}

Abbink, K. and H. Hennig-Schmidt. 2002. "Neutral versus Loaded Instructions in a Bribery Experiment,” University of Nottingham, CeDEx Working Paper 2002-13.

Abbink, K., B. Irlenbusch and E. Renner (2002), “An Experimental Bribery Game,” Journal of Law, Economics and Organization, 18(2), 428-454.

Alatas, V., L. Cameron, A. Chaudhuri, N. Erkal, and L. Gangadharan. 2006. "Gender and Corruption: Insights from an Experimental Analysis," University of Melbourne Working Paper.

Alevy, J., M. Haigh, and J. List. 2006. "Information Cascades: Evidence from a Field Experiment with Financial Market Professional,” Journal of Finance, forthcoming.

Bardhan, P. 1997. "Corruption and Development: A Review of Issues," Journal of Economic Literature, 35, 1320-1346.

Bardhan, P. 2006. "The Economist's Approach to the Problem of Corruption," World Development, 34(2), 341-348.

Barr, A., M. Lindelow, and P. Serneels. 2004. "To Serve the Community or Oneself: The Public Servant’s Dilemma,” World Bank Policy Research Working Paper, 3187.

Burns, P. 1985. "Experience and Decision Making: A Comparison of Students and Businessmen in a Simulated Progressive Auction,” in V. L. Smith (ed), Research in Experimental Economics, JAI Press.

Cadsby, C. and E. Maynes. 1998. "Choosing between a Socially Efficient and Free-riding Equilibrium: Nurses versus Economics and Business Students," Journal of Economic Behavior and Organization, 37(2), 183-192.

Cameron, L., A. Chaudhuri, N. Erkal, and L. Gangadharan. 2006. "Propensities to Engage in and Punish Corrupt Behavior: Experimental Evidence from Australia, India, Indonesia, and Singapore,” University of Melbourne Working Paper.

Carbone, E. 2005. “Demographics and Behaviour,” Experimental Economics, 8, 217-232.

Carpenter, J., E. Verhoogen, and S. Burks. 2005. “Comparing Students to Workers: The Effects of Stakes, Social Framing, and Demographics on Bargaining Outcomes”, in J. Carpenter, G. Harrison, and J. List (eds), Field Experiments in Economics, JAI Press.

Cadsby, C. and E. Maynes. 1998. "Choosing between a Socially efficient and Free-Riding Equilibrium: Nurses versus Economics and Business Students," Journal of Economic Behavior and Organization, 37(2), 183-192. 
Cooper D. and J. Kagel. 2003. "The Impact of Meaningful Context on Strategic Play in Signalling Games,” Journal of Economic Behavior and Organization, 50(3), 311337.

Cooper, D., J. Kagel, W. Lo, and Q. Gu. 1999. "Gaming Against Managers in Incentive Systems: Experimental Results with Chinese Students and Chinese Managers," American Economic Review, 89(4), 781-804.

Croson, R. and U. Gneezy. 2004. "Gender Differences in Preferences: A Review of Economics Experiments,” at opim.wharton.upenn.edu/ crosonr/publications.html.

Fehr, E. and J. List. 2004. "The Hidden Costs and Returns of Incentives - Trust and Trustworthiness among CEOs," Journal of the European Economic Association, 2(5), 743-71.

Gick, M. and K. Holyoak. 1980. “Analogical Problem Solving,” Cognitive Psychology, 12(3), 306-55.

Harrison, G. W. and J. A. List. 2004. "Field Experiments," Journal of Economic Literature, 42(4), 1013-1059.

Harrison, G. and J. List. 2005. "Naturally Occurring Markets and Exogenous Laboratory Experiments: A Case Study of the Winner's Curse," at www.bus.ucf.edu/wp/content/archives/03-14Glenn.pdf.

Kaufman, D. 2005. "10 Myths About Governance and Corruption," Finance and Development, 42(3), 41-43.

Kovalchik, S., C. Camerer, D. Grether, C. Plott, and J. Allman. 2004. “Aging and Decision Making: A Comparison between Neurologically Healthy Elderly and Young Individuals,” Journal of Economic Behavior and Organization, 58, 79-94.

Levitt, S. and J. List. 2006. "What do Laboratory Experiments Tell Us About the Real World?” at pricetheory.uchicago.edu/levitt/LevittCV.html.

List, J. 2003. “Does Market Experience Eliminate Market Anomalies?” Quarterly Journal of Economics, 118(1), 41-71.

Olken, Benjamin. 2006. “Corruption Perceptions vs. Corruption Reality,” available at http://www.nber.org/ bolken/.

Perkins, D. and G. Salomon. 1988. “Teaching for Transfer,” Educational Leadership, 46(1), 22-32. 
Potters, J. and F. van Winden. 1996. "The Performance of Professionals and Students in an Experimental Study of Lobbying," at papers.ssrn.com/sol3/papers.cfm?abstract_id=2067.

Salomon, G. and D. Perkins. 1989. "Rocky Roads to Transfer: Rethinking Mechanisms of a Neglected Phenomenon,” Educational Psychologist, 24(2), 113-42. 


\section{Figure 1}

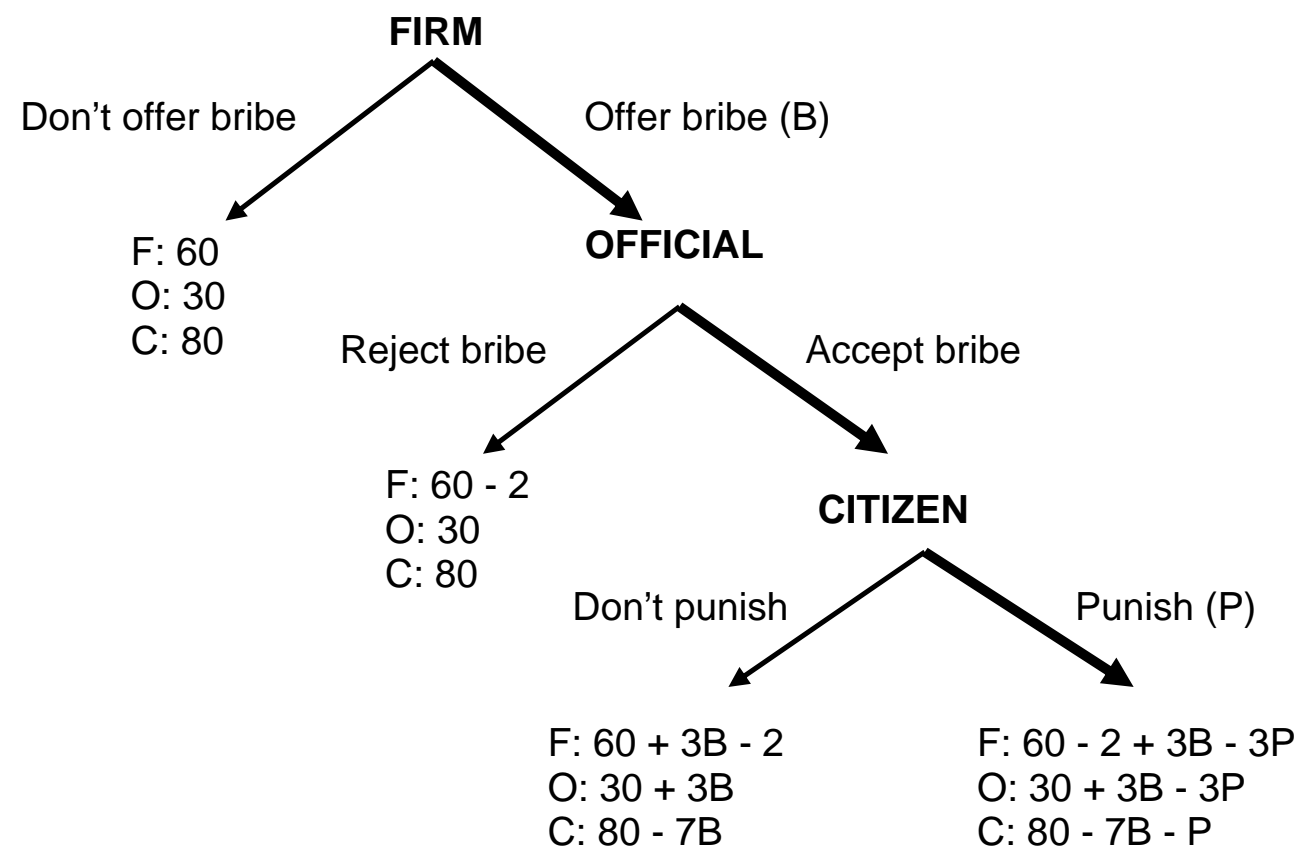


Figure 2: Firm behavior

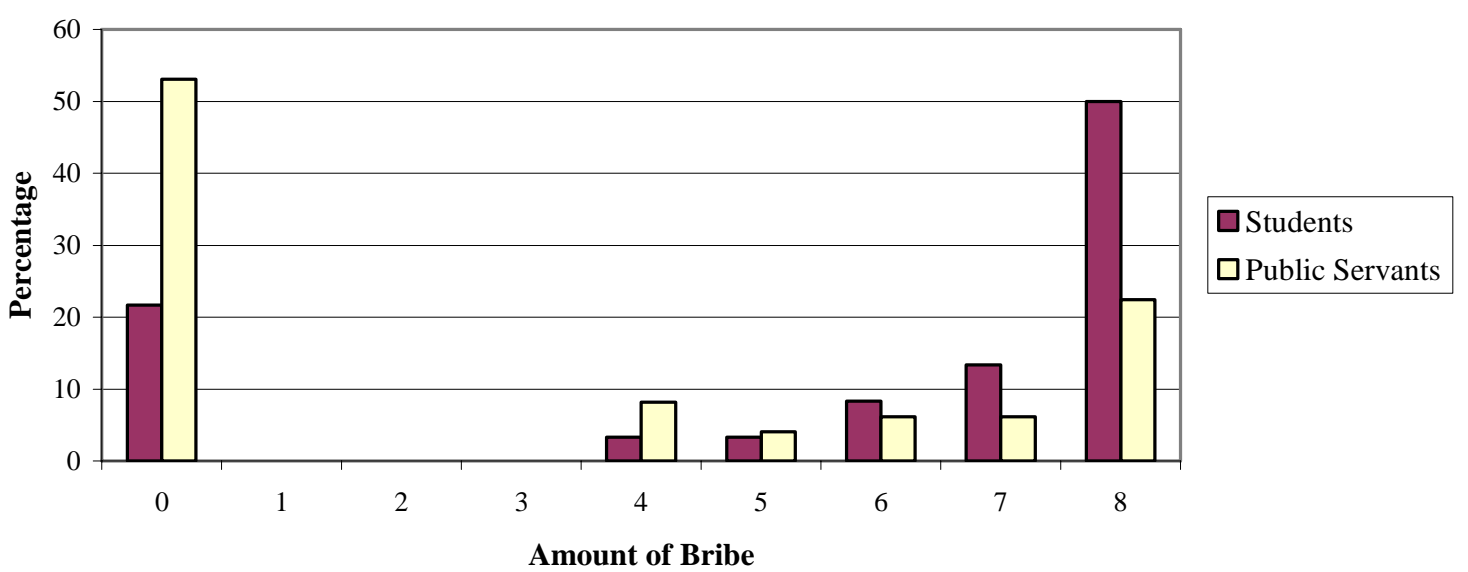

Figure 3: Acceptance Rates

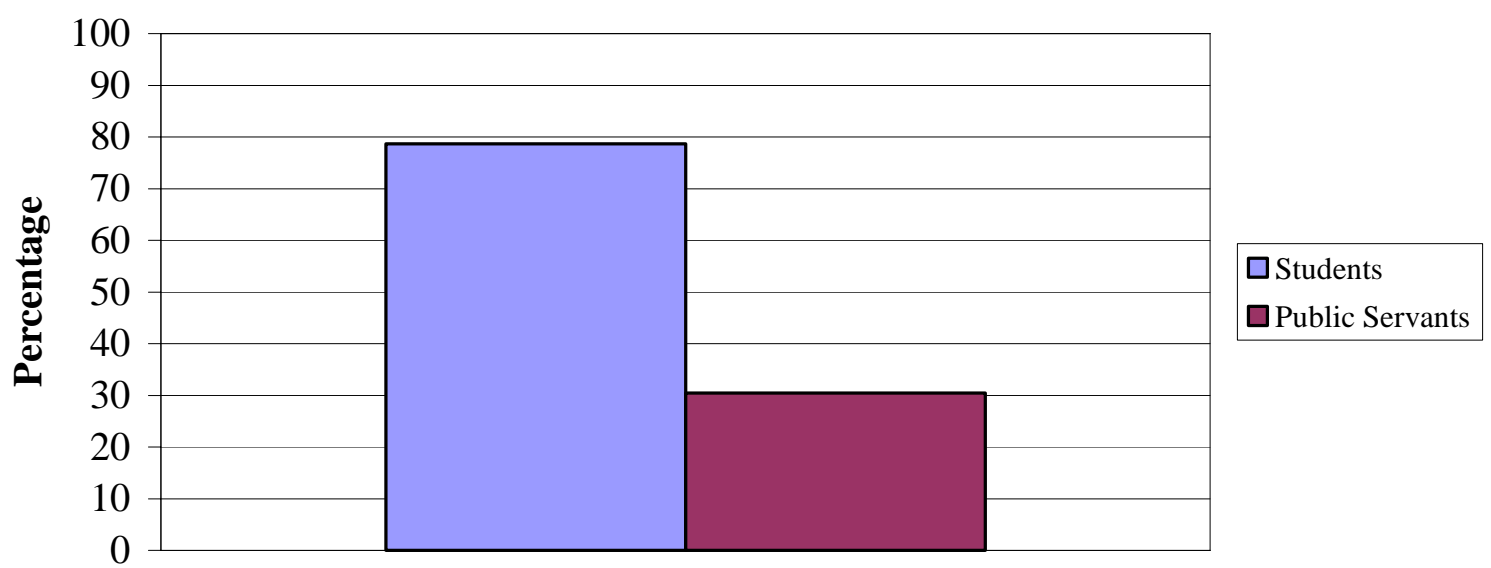


Figure 4: Punishment Behavior

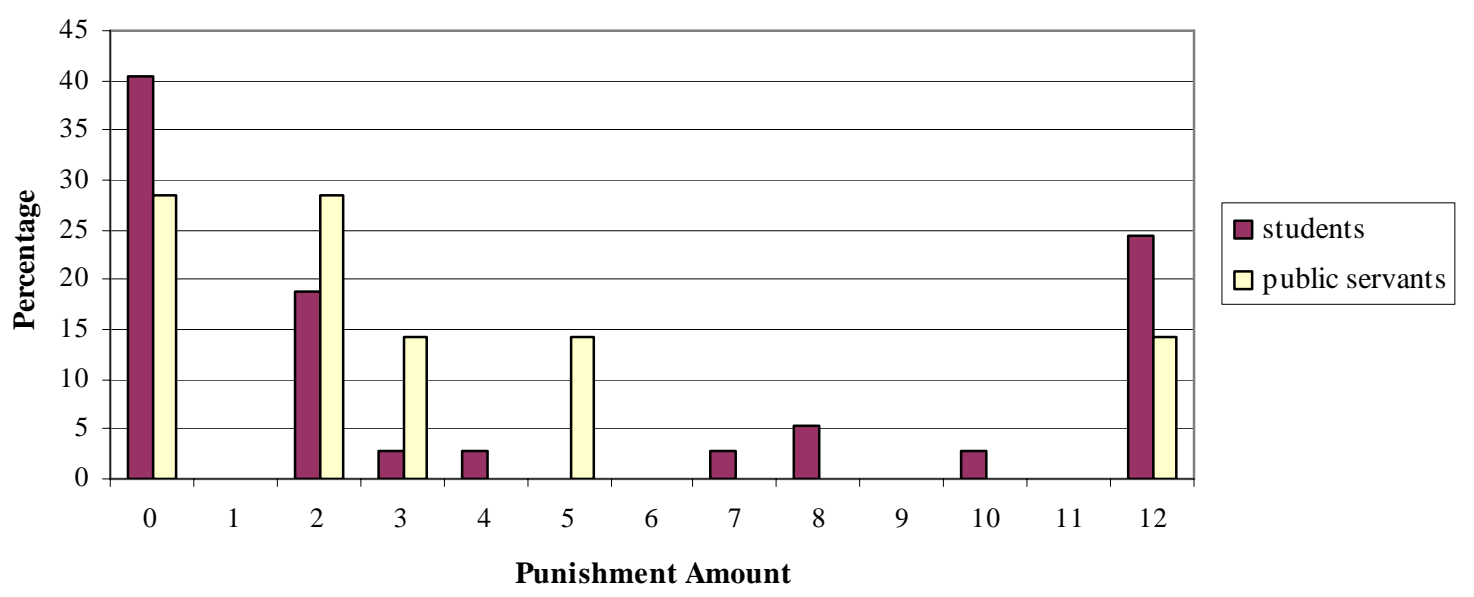


Table 1: Subject Pool Characteristics

\begin{tabular}{lcc}
\hline \multirow{2}{*}{ VARIABLES } & Students & Public Servants \\
\cline { 2 - 3 } & Mean & Mean \\
Age & 20.6 & 30.5 \\
Male & 0.42 & 0.75 \\
Urban & 0.89 & 0.7 \\
Work Experience (years) & 0.36 & 8.5 \\
Intention to Work in the Public Sector: & 0.19 & - \\
Weekly Expenditure (Rp) & 110534 & 245711 \\
Religion: & & \\
$\quad$ Islam & 0.664 & 0.849 \\
$\quad$ Catholic & 0.13 & 0.041 \\
$\quad$ Protestant & 0.2 & 0.11 \\
$\quad$ Hindu & 0.006 & 0 \\
Ethnicity: & & \\
$\quad$ Javanese & 0.49 & 0.36 \\
$\quad$ Chinese & 0.12 & 0 \\
$\quad$ Sudanese & 0.08 & 0.1 \\
$\quad$ Batak & 0.11 & 0.2 \\
$\quad$ Minang & 0.07 & 0.06 \\
$\quad$ Other & 0.19 & 0.28 \\
Hear about or come in contact with Corruption: & & \\
personally in your workplace & 0.09 & 0.55 \\
personally outside your workplace & 0.33 & 0.32 \\
via friends/family & 0.52 & 0.24 \\
via mass media (TV, newspaper, radio) & 0.74 & 0.57 \\
no contact & 0.09 & 0.1 \\
\hline
\end{tabular}




\section{Table 2: T-tests of Statistical Difference}

\begin{tabular}{lrlrlc}
\hline & \multicolumn{2}{c}{ Students } & \multicolumn{2}{c}{ Public Servants } & p-value \\
\cline { 2 - 6 } \% of firms bribing & 78.3 & $(\mathrm{~N}=60)$ & 46.9 & $(\mathrm{~N}=49)$ & 0.0005 \\
Bribe amount (if $>0)$ & 7.3 & $(\mathrm{~N}=47)$ & 6.65 & $(\mathrm{~N}=23)$ & 0.04 \\
\% officials accepting & 78.7 & $(\mathrm{~N}=47)$ & 30.4 & $(\mathrm{~N}=23)$ & 0 \\
\% citizens punishing & 0.59 & $(\mathrm{~N}=37)$ & 0.71 & $(\mathrm{~N}=7)$ & 0.56 \\
Punishment amount $($ if $>0)$ & 7.4 & $(\mathrm{~N}=22)$ & 4.8 & $(\mathrm{~N}=5)$ & 0.26 \\
\hline
\end{tabular}


Table 3: Regression Results

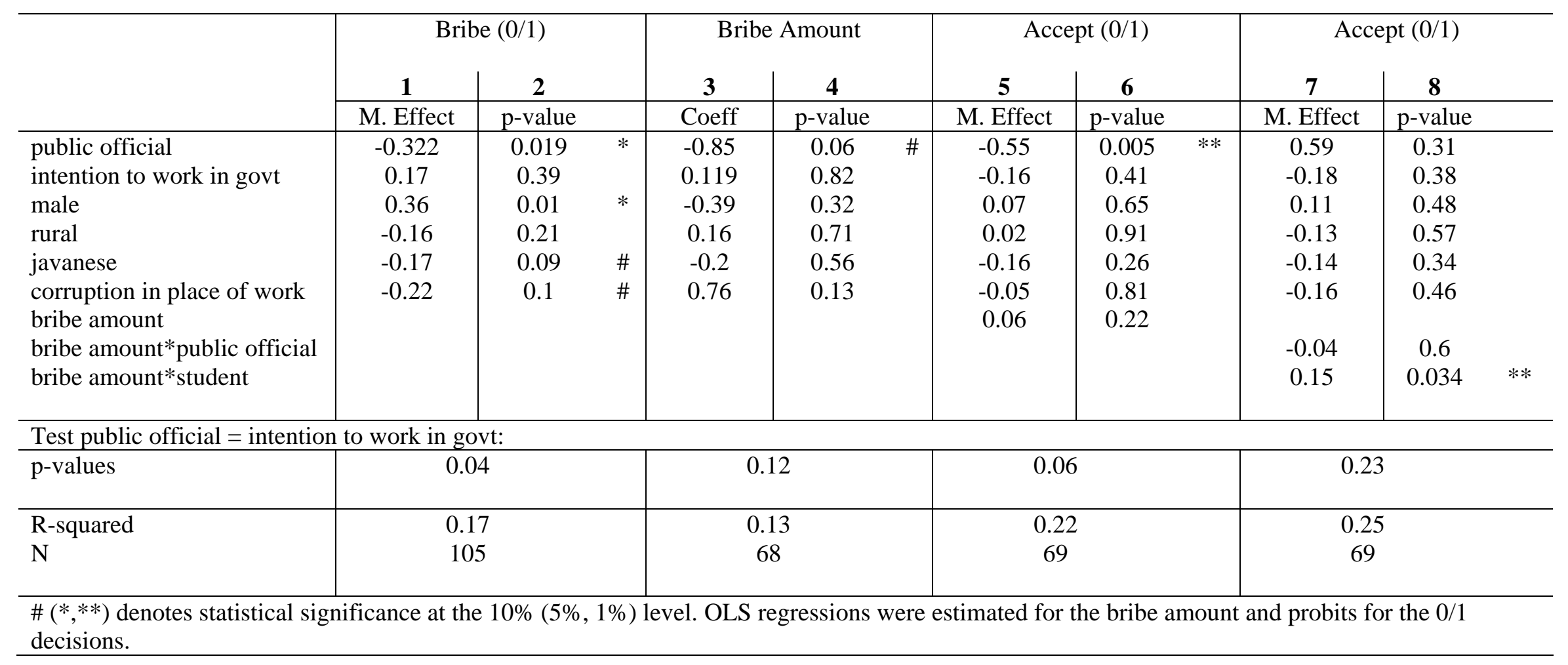


Table 4: Reasons for Observed Behavior

\begin{tabular}{|c|c|c|c|c|c|c|c|c|c|c|}
\hline \multirow[b]{2}{*}{ FIRMS } & & \multicolumn{3}{|c|}{ All } & \multicolumn{2}{|c|}{ If bribe } & \multicolumn{4}{|c|}{ If don't bribe } \\
\hline & & Officials & Students & & Officials & Students & & Officials & Students & \\
\hline \multicolumn{11}{|l|}{ Bribe? } \\
\hline \multirow[t]{3}{*}{ Yes } & necessary given the current environment & 0.39 & 0.28 & & 0.83 & 0.36 & $* *$ & 0 & 0 & \\
\hline & for the social/economic good of the country (e.g. reduce unemployment) & 0.04 & 0.02 & & 0.09 & 0.02 & & 0 & 0 & \\
\hline & to see the response of the official/citizen & 0 & 0.08 & * & 0 & 0.11 & & 0 & 0 & \\
\hline \multirow[t]{4}{*}{ No } & Morality & 0.18 & 0.17 & & 0 & 0 & & 0.35 & 0.77 & * \\
\hline & to reduce corruption (social costs) & 0.25 & 0 & $* *$ & 0 & 0 & & 0.46 & 0 & $* *$ \\
\hline & profit-maximisation (in the long run it is bad for the firm) & 0.18 & 0.03 & ** & 0 & 0 & & 0.35 & 0.15 & \\
\hline & Equity & 0 & 0.1 & * & 0 & 0.02 & & 0 & 0.38 & $* *$ \\
\hline \multirow[t]{2}{*}{$\mathrm{N}$} & & 49 & 60 & & 23 & 47 & & 26 & 13 & \\
\hline & & \multicolumn{3}{|c|}{ All } & \multicolumn{2}{|c|}{ If accept } & & \multicolumn{3}{|c|}{ If don’t accept } \\
\hline OFFICIALS & & Officials & Students & & Officials & Students & & Officials & Students & \\
\hline \multicolumn{11}{|l|}{ Accept? } \\
\hline \multirow[t]{4}{*}{ Yes } & necessary for firms to bribe/will be able to help the firm & 0.09 & 0.06 & & 0.29 & 0.08 & & 0 & 0 & \\
\hline & necessary because salaries are low & 0.09 & 0.02 & & 0.14 & 0.03 & & 0 & 0 & \\
\hline & payoff maximization & 0.04 & 0.62 & ** & 0.14 & 0.78 & ** & 0 & 0 & \\
\hline & Equity & 0 & 0.06 & & 0 & 0.08 & & 0 & 0 & \\
\hline \multirow[t]{6}{*}{ No } & Morality & 0.35 & 0.06 & $* *$ & 0 & 0 & & 0.5 & 0.3 & \\
\hline & to reduce corruption & 0.09 & 0.09 & & 0 & 0 & & 0.13 & 0.3 & \\
\hline & scared of implications/risk & 0 & 0 & & 0 & 0 & & 0 & 0 & \\
\hline & payoff maximization & 0.04 & 0.06 & & 0 & 0 & & 0.06 & 0.3 & \\
\hline & Fairness & 0 & 0.02 & * & 0 & 0 & & 0.06 & 0.1 & \\
\hline & bribe too small & 0.09 & 0 & & 0 & 0 & & 0.125 & 0 & \\
\hline \multirow[t]{2}{*}{$\mathrm{N}$} & & 23 & 47 & & 7 & 37 & & 16 & 10 & \\
\hline & & \multicolumn{2}{|c|}{ All } & & \multicolumn{2}{|c|}{ If punish } & & \multicolumn{2}{|c|}{ If don’t punish } & \\
\hline CITIZENS & & Officials & Students & & Officials & Students & & Officials & Students & \\
\hline \multicolumn{2}{|l|}{ Punish? } & & & & & & & & & \\
\hline \multirow[t]{4}{*}{ Yes } & Moral & 0.43 & 0.35 & & 0.6 & 0.59 & & 0 & 0 & \\
\hline & reduce corruption & 0.29 & 0.16 & & 0.4 & 0.27 & & 0 & 0 & \\
\hline & fairness & 0 & 0.03 & & 0 & 0.05 & & 0 & 0 & \\
\hline & negative reciprocity & 0.14 & 0.05 & & 0.2 & 0.09 & & 0 & 0 & \\
\hline \multirow[t]{3}{*}{ No } & payoff maximisation & 0 & 0.35 & \# & 0 & 0 & & 0 & 0.87 & $* *$ \\
\hline & difficult to change system & 0 & 0 & & 0 & 0 & & 0 & 0 & \\
\hline & bribe may be for good purpose/necessary & 0.29 & 0.22 & & 0 & 0 & & 1 & 0.53 & \\
\hline $\mathrm{N}$ & & 7 & 37 & & 5 & 22 & & 2 & 10 & \\
\hline
\end{tabular}




\section{University Library}

\section{- M M N E R VA A gateway to Melbourne's research publications}

Minerva Access is the Institutional Repository of The University of Melbourne

\section{Author/s:}

Alatas, Vivi;CAMERON, LISA;Chaudhuri, Ananish;ERKAL, NISVAN;GANGADHARAN, LATA

Title:

Subject pool effects in a corruption experiment: a comparison of Indonesian public servants and Indonesian students

\section{Date:}

2006-10

\section{Citation:}

Alatas, Vivi and Cameron, Lisa and Chaudhuri, Ananish and Erkal, Nisvan and Gangadharan, Lata (2006) Subject pool effects in a corruption experiment: a comparison of Indonesian public servants and Indonesian students.

Persistent Link:

http://hdl.handle.net/11343/34442 